\title{
Editorial for EAIT Issue 2, 2018
}

\author{
Arthur Tatnall ${ }^{1}$
}

Published online: 26 February 2018

(C) Springer Science+Business Media, LLC, part of Springer Nature 2018

Before looking at the contents of this issue I will tell you about the Encyclopedia of Education and Information Technologies (Springer) that is currently accepting articles. This encyclopedia will cover all aspects of the use of computers and information technology in parts and forms of education. It will cover topics including: Computing in Early Childhood Education, Computers in Primary Schools, Computers in Secondary Schools, Professional Training and Professional Development, Computers in Universities, Computers in Training Colleges, Life-Long Learning, Assistive Technologies for Special Education and People with Disabilities, Teaching Subjects, History of Educational Computing, Educational Resources, Educational Games, Mobile Technologies, Designing new Educational Products, Innovation and Adoption, Teachers and IT, Computing Education Research, Digital Literacy, Classroom Use, Online learning, Global Policies and Issues, Social Networking, Developed and Developing Countries, Educational Assessment, Educational Management and Sociocultural Issues and Technology. If you are interested in submitting an article or if you have a recent paper that, if modified, might be suitable, please contact me (Arthur.Tatnall@vu.edu.au) for more details. The encyclopedia website is: https://meteor.springer.com/project/dashboard.jsf?id=509.

This issue of EAIT journal has articles from researchers in Australia, Canada, UAE, Brazil, USA, Thailand, Sweden, Israel, Estonia, Greece, Malaysia, UK, India, Kazakhstan, Spain, Morocco and Finland.

The first article in this issue: Social media in higher education: A literature review of Facebook comes from Ritesh Chugh (Central Queensland University, Australia) and Umar Ruhi (University of Ottawa, Canada) (https://doi.org/10.1007/s10639-017-96212 ). They begin with the observation that the rapid adoption of social media technologies has resulted in a fundamental shift in how communication and collaboration take place, and so it is important to explore how these are being used as educational tools. Their paper explores the ways in which Facebook is used for learning and teaching. The

Arthur Tatnall

Arthur.Tatnall@vu.edu.au

1 Victoria University, Box 14428, Melbourne, PO 8001, Australia 
paper highlights the problems and limitations of Facebook and offers guidelines to encourage social media adoption.

Next comes an article by Ieda M. Santos (Emirates College for Advanced Education, UAE), Otávio Bocheco (Federal Institute Catarinense Campus Rio do Sul, Brazil) and Claudine Habak (Emirates College for Advanced Education, UAE). They offer: $\boldsymbol{A}$ survey of student and instructor perceptions of personal mobile technology usage and policies for the classroom (https://doi.org/10.1007/s10639-017-9625-y). Their study explored perceptions of personal mobile device usage and policies for appropriate practices in the classrooms at a Brazilian higher education institution. Results suggest that students occasional used WhatsApp or similar applications despite the strict policies adopted by many of the instructors, and student being awareness of disruptions.

A survey of K-12 teachers' utilization of social networks as a professional resource by Leah J. Hunter and Cristin M. Hall (The Pennsylvania State University, USA) follows (https://doi.org/10.1007/s10639-017-9627-9). Again, dealing with social media, but this time by teachers looking for educational resources, their study offers results from a survey examining patterns of social network application use among K-12 teachers in the United States. These results provide a user update on factors that predict overall engagement with social networks, which included comfort and trust in their use, as well as their age. The article also looks at the most popular applications used by teachers and the reasons for their use.

The article that follows: Students' participation in peer-to-peer communication supported by social media is by Siriporn Mikum (King Mongkut's University of Technology Thonburi, Thailand), Surachai Suksakulchai (King Mongkut's University of Technology Thonburi, Thailand), Settachai Chaisanit (Sripatum University Chonburi Campus, Thailand) and Elizabeth Murphy (Memorial University of Newfoundland, Canada) (https://doi.org/10.1007/s10639-017-9628-8). They observe that social media supports new approaches to learning that rely on voluntary, peer-to-peer communication using devices and software provided and managed by students rather than on institutional course management systems. Encouraging students to ask questions about course content can result in improved performance and so understanding how students participate and what drives them to participate can provide insights into how universities and instructors can be socially ready.

The relationship between sources of self-efficacy in classroom environments and the strength of computer self-efficacy beliefs points out that motivation and success in computer-science courses are influenced by the strength of students' self-efficacy beliefs in their learning abilities (https://doi.org/10.1007/s10639-017-9630-1). It was contributed by: Yuwarat Srisupawong (King Mongkut's University of Technology Thonburi, Thailand), Ravinder Koul (The Pennsylvania State University, USA), Jariya Neanchaleay (King Mongkut's University of Technology Thonburi, Thailand), Elizabeth Murphy (Memorial University of Newfoundland, Canada) and Emmanuel Jean Francois (Ohio University, Athens, USA). The authors point out that those students with weak self-efficacy may struggle to be successful in a computer-science course, and their reported study investigates factors that enhance or impede the computer self-efficacy of these students. Their results showed that perceptions of a classroom learning environment with autonomy, meaningfulness, and involvement were positively associated with strong computer self-efficacy. 
Annika Lantz-Andersson (University of Gothenburg, Sweden) then presents: Language play in a second language: Social media as contexts for emerging Sociopragmatic competence (https://doi.org/10.1007/s10639-017-9631-0). The reported study aimed to gain insights into students' language use on social media as part of the specific linguistic activities of second language learning, including development of sociopragmatic competence. The findings showed that the social media context offered a casual space for communication in which the students, by attentively attuning to the local coordinated framing, used diverse linguistic repertoires to play with the language. The author suggests that language play on social media can be seen as a valuable activity in developing sociopragmatic competence.

The following article points out that the teacher-student relationship is vital for students' academic, emotional and social development, as well as for teachers' professional and personal development. Broadening communication yet holding back: Teachers' perceptions of their relationship with students in the SNS-era is by Alona Forkosh-Baruch (Levinsky College of Education, Israel) and Arnon Hershkovitz (Tel Aviv University, Israel), and their quantitative study examines teacherstudent communication and relationships on Facebook among secondary school teachers (https://doi.org/10.1007/s10639-017-9632-z). Overall, teachers were interested in broadening communication channels with students in order to empower learning and interpersonal relationships, but also to maintain traditional teacher-student differentiation.

Perceptions of technological, pedagogical and content knowledge (TPACK) among pre-service teachers in Estonia comes from Piret Luik, Mere Taimalu and Reelika Suviste (University of Tartu, Estonia) and points out that preparing quality teachers for twenty-first century students is an essential task for teacher training institutions (https://doi.org/10.1007/s10639-017-9633-y). As well as gaining skills to teach effectively, teachers should also know how to integrate digital technologies into their teaching. In this study a generally applicable instrument for measuring the TPACK framework was created. The research aimed to validate the created instrument and to find out how pre-service teachers perceive their technological, pedagogical and content knowledge regarding the TPACK framework in Estonia, which is a technologically highly developed country where technology is broadly used in general education.

The educational potentials and challenges of 'flipping' a classroom are today welldocumented, but the next article asks: Is the flipped classroom model for all? Correspondence analysis from trainee instructional media designers and was written by Nikolaos Pellas (University of the Aegean, Greece) (https://doi.org/10.1007/s10639017-9634-x). Literature on the benefits in using the flipped model as a socially inclusive technology supported instructional design model is still in its infancy and the reported study investigated the perceptions of twenty-six trainee instructional media designers based on the access and use of a flipped instructional model, following exploratory mixed method research with quantitative and qualitative data that was framed by learning concepts.

An empirical investigation of campus portal usage is an article by Mohsen Saghapour (University of Malaya), Mohammad Iranmanesh (Multimedia University), Suhaiza Zailani (University of Malaya) and Gerald Guan Gan Goh (Multimedia University), Malaysia (https://doi.org/10.1007/s10639-017-9635-9). This reported study examined the determinants of the perceived ease of use and perceived 
usefulness of a campus portal, and their influence on its usage. Their results showed that the ease of finding and of understanding have a positive impact on the perceived ease of use of the portal. It suggests that perceived ease of use and usefulness are vital towards enhancing the usage frequency and volume of the campus portal.

Maria Limniou, Ian Schermbrucker and Minna Lyons (all from the University of Liverpool, UK) next write on: Traditional and flipped classroom approaches delivered by two different teachers: the student perspective with the aim for students to express their views on teaching approaches delivered by two teachers under the perspectives of Higher Order Thinking Skills development and their preferences on learning material and learning activities (https://doi.org/10.1007/s10639-017-9636-8). The first year psychology students followed both the traditional and a flipped classroom approach delivered by two different teachers, with one teacher introducing them to social and the other to clinical psychology. The reported investigation concluded that the intricate relationship between the choice of learning material and activities, and the teacher's contribution to the flipped classroom approach and their expectation/behaviour toward technology was important.

Next, an article by Pragya Dwivedi (Motilal Nehru National Institute of Technology Allahabad), Vibhor Kant (The LNM Institute of Information Technology) and Kamal K. Bharadwaj (Jawaharlal Nehru University New Delhi), India looks at: Learning path recommendation based on modified variable length genetic algorithm (https://doi. org/10.1007/s10639-017-9637-7). They note that with the rapid advancement of information and communication technologies, e-learning has gained considerable attention in recent years and many researchers have developed e-learning systems with personalised learning. Curriculum sequencing is an important concern for developing more efficient personalised e-learning systems. In their paper they present a learning path recommendation system for e-learners through a variable length genetic algorithm by considering learning styles and knowledge levels.

Using Socrative as an online homework platform to increase students' exam scores describes research by Nuri Balta (Almaty Management University, Kazakhstan), Víctor-Hugo Perera-Rodríguez (University of Seville, Spain and Universidad de Sevilla, C/ Pirotecnia, Spain) and Carlos Hervás-Gómez (University of Seville, Spain) (https://doi.org/10.1007/s10639-017-9638-6). Socrative is an online assessment and student response tool that provides opportunities to increase student engagement in the classroom. The article describes how Socrative was used as an online homework completing platform to increase students' exam scores in physics. Results of the research showed that students have moderately positive attitudes toward the use of Socrative and indicated that its use can go beyond engaging and motivating them.

Digital educational games and mathematics. Results of a case study in primary school settings was contributed by Emmanuel Fokides (University of the Aegean, Greece) and presents the results of a project in which a series of digital games were used for teaching Mathematics to first, fourth, and sixth-grade primary school students (https://doi.org/10.1007/s10639-017-9639-5). Mathematics was selected because of the difficulties students face in understanding basic maths concepts and although digital games are used quite extensively for educational purposes, they are scarcely used for teaching Mathematics. The games were developed by the teachers using Microsoft's Kodu Game Lab. Learning outcomes were compared to two other groups of students, one was taught using the model proposed by Driver and Oldham and the second taught 
conventionally. Results indicated that, in most cases, students in the games group outperformed students in the other groups.

The next article describes how an online support distance-learning program in Mathematics was developed to aid first year engineering students for their transition from secondary to tertiary education, in order to reinforce deficiencies they may have in mathematical knowledge. An analysis of first year engineering students' satisfaction with a support distance learning program in mathematics comes from Nikolaos $M$. Matzakos (School of Pedagogical and Technological Education, Greece) and Michail Kalogiannakis (University of Crete, Greece) (https://doi.org/10.1007/s10639-0179641-y). Their study aimed to examine the extent to which such a program helped students to familiarise themselves with distance learning programs, their satisfaction with the material of the program and their attitudes towards a conventional support learning program in Mathematics.

The article that follows: Using cloud computing services in e-learning process: Benefits and challenges is by Abderrahim El Mhouti (Mohamed First University, Oujda, Morocco), Mohamed Erradi and Azeddine Nasseh (both from Abdelmalek Essaadi University, Morocco) (https://doi.org/10.1007/s10639-017-9642-x). Use of elearning has become a very popular educational trend but with the huge growth in the number of users, data and educational resources generated, e-learning systems have become more and more expansive in terms of hardware and software resources and many educational institutions cannot afford such ICT investments. The advantages of cloud computing technology make it a natural platform to provide support to e-learning systems and this article focuses on research on the application of cloud computing in e-learning.

Towards automated e-counselling system based on counsellors' emotion perception deals with emotions and counselling and was contributed by Emmanuel Awuni Kolog and Calkin Suero Montero (University of Eastern Finland) (https://doi. org/10.1007/s10639-017-9643-9). They point out that emotions are a core semantic component of human communication and counsellors own emotional state could affect their intuitional effort when taking decisions concerning their clients. This makes the accuracy of detected emotions by counsellors doubtful and highlights a need for complementing the intuitional effort of counsellors by a computational approach and ascertaining the efficacy of computational algorithms. The result of their research shows strong intra-counsellor annotation agreement of emotions while intercounsellors annotation agreement was low.

Factors, issues and interdependencies in the incorporation of a Web 2.0 based learning environment in higher education is by Theodoros Karvounidis, Konstantinos Chimos, Sotirios Bersimis and Christos Douligeris (all from the University of Piraeus, Greece) (https://doi.org/10.1007/s10639-017-9644-8). Their article investigates the effect that a Web 2.0 learning environment may have in higher education to add value to the students' existing competencies, and whether the incorporation of such an environment has an effect on the students' performance. It also looks at the significant factors that should be taken into account in the deployment of these technologies to achieve the maximum possible benefits and whether and how they correlate to each other.

Learning Analytics is an emerging field in which sophisticated analytic tools are used to improve learning and education, and Application of learning analytics using 
clustering data Mining for Students' disposition addresses this topic. Sanyam Bharara, Sai Sabitha and Abhay Bansal (all from Amity University Uttar Pradesh, India) point out that this is closely tied to a series of other fields of study like business intelligence, web analytics, academic analytics, educational data mining and action analytics (https://doi.org/10.1007/s10639-017-9645-7). The main objective of the described research was to find meaningful indicators or metrics in a learning context and to study the inter-relationships between these metrics using the concepts of Learning Analytics and Educational Data Mining, so analysing the effects of different features on student's performance using Disposition analysis.

The final article deals with ubiquitous learning and the use of ubiquitous learning environments in higher education. Ubiquitous learning environments in higher education: A scoping literature review, from Mari Aulikki Virtanen (University of Oulu, Finland), Elina Haavisto (University of Turku, Finland), Eeva Liikanen (Tampere University of Applied Sciences, Finland) and Maria Kääriäinen (University of Oulu, Finland) points out that ubiquitous learning environments can enhance context aware and seamless learning experiences available from any location at any time, supporting smooth interaction between authentic and digital learning resources and providing personalised learning opportunities (https://doi.org/10.1007/s10639-017-9646-6). The described scoping review was to identify criteria for ubiquitous learning environments and to summarise the relevant knowledge in this research area.

In addition to the normal issues of EAIT, from time to time we offer Special Issues on a specific topic within education and information technologies. If you have any ideas for a Special Issue of EAIT that you would like to Guest Edit, please contact me (Arthur.Tatnall@vu.edu.au) to discuss this.

\section{Arthur Tatnall}

Editor-in-Chief 